See discussions, stats, and author profiles for this publication at: https://www.researchgate.net/publication/329278326

\title{
Full-Bodied Taste: On the Embodied Origins of Product Perception and
} Sensory Evaluation: Designing New Product Experiences

Chapter · January 2019

DOI: 10.1007/978-3-319-94977-2_ 7

CITATION

1

2 authors:

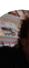

Thomas Van Rompay

University of Twente

76 PUBLICATIONS 1,372 CITATIONS

SEE PROFILE

Some of the authors of this publication are also working on these related projects:

Design for Lifelong Sports Experience View project

fMRI research View project
READS

336

Bob Fennis

University of Groningen

90 PUBLICATIONS 2,179 CITATIONS

SEE PROFILE 
HEADER: EMBODIMENT IN MULTISENSORY PACKAGING DESIGN

Full-Bodied Taste:

On the Embodied Origins of Product Perception and Sensory Evaluation

\author{
Thomas J. L. van Rompay ${ }^{1}$ \& Bob M. Fennis ${ }^{2}$ \\ ${ }^{1}$ University of Twente, Enschede, The Netherlands \\ ${ }^{2}$ University of Groningen, Groningen, The Netherlands
}

*Corresponding author:

Thomas van Rompay, University of Twente, Department of Communication Science, P.O. Box 217, 7500 AE Enschede, The Netherlands. Email: t.j.l.vanrompay@utwente.nl. 


\begin{abstract}
Packaging design is not only an indispensable marketing tool, but also an important vehicle for shaping sensory evaluations and for nudging healthy food choices. However, insights specifying how the 'look and feel' properties of product packaging design influence evaluations and sensory impressions such as taste and smell are lacking, thus thwarting informed decision making regarding the selection of the most appropriate design elements. The aim of the present chapter is therefore to demonstrate how an embodied perspective can account for effects of design variables on consumer evaluations. Specifically, the influence of design variables relating to: 1) packaging shape, 2) graphic layout and composition, and 3) tactile packaging properties will be discussed in light of recent studies based on the embodied cognition framework. In doing so, moderators of design influences pertaining to the consumer and the environmental context are discussed. Furthermore, as packaging designs always comprise a multitude of design factors, we will elaborate on their interplay, and on how (mis)matches between expectations generated by packaging design and sensory impressions on experiencing the product can influence information processing and evaluation. Finally, we discuss avenues for future product development, research, and design for behaviour change initiatives.
\end{abstract}

KEYWORDS: Embodiment; packaging design; multisensory food experience; consumer cognition; symbolic meaning. 


\section{Introduction}

Situated at the interface of advertising and the visual arts, packaging design has for many years attracted the interest of researchers, designers and artists alike. Consider, for instance, industrial designer Raymond Loewy, whose graphic designs for, amongst others, Lucky Strike and LU (a French producer of biscuits and cookies) have become iconic. Or consider American artist Andy Warhol and his famous blown-up (Campbell's) soup cans, which in 2012 inspired a special edition ‘soup’ series by that same brand. Little did Loewy and Warhol realize that their designs for food manufacturers have done more than just trigger amusement and delight, but that their designs may well have influenced consumers' actual consumption experiences. Indeed, recent research, discussed in this chapter, convincingly shows that packaging design (for all kinds of foods and beverages) shapes consumers' (sensory) experiences during food and beverage consumption (e.g., Krishna, 2012; Spence \& Gallace, 2012a).

By virtue of this direct relationship between packaging and contents, and by being physically present at an ever-widening array of consumer choice contexts (ranging from supermarkets and gas stations to schools, libraries, and sports facilities) packaging design is obviously of great importance to both marketers and brand managers. For instance, in 2015, Heineken reenergized one of its Mexican beer brands with new colours and a distinctive matt finish, suggestive of a more masculine personality. In contrast to traditional tools of persuasion (e.g., slogans or product claims) through which meanings are communicated explicitly by advertisers, such design cues may induce more implicit consumer-generated attributions of brand meaning (Deng \& Kahn, 2009; Krishna, 2012; Peracchio \& MeyersLevy, 2005).

Finally, from a societal perspective, packaging design may stimulate healthy food consumption. For instance, the look and feel properties of product packaging have been 
shown to influence sweetness evaluations in taste sample tests (e.g., Van Rompay, Finger, Saakes, \& Fenko, 2017). Such findings attest to the feasibility of managing sugar contents (and other less than healthy ingredients) without necessarily 'spoiling' the experience (at least in the short-term). In other words, packaging design may be an important tool for overcoming health-compromising heuristics consumers may entertain such as 'healthy is not tasty' (Raghunathan, Naylor, \& Hoyer, 2006). As of yet, however, no evidence-based designs and systematic evaluations thereof (testifying to the feasibility of such an approach) have seen the light of day. Arguably, the main reason for this is that (notwithstanding the promise of new technologies allowing for the creation of ever more advanced and sensory-rich packaging designs), our understanding of why and how specific packaging properties steer consumer decision making and influence sensory experiences is still in its infancy.

\section{Aims and approach}

Taking note of the great potential of packaging design for managing sensory experiences and consumer decision-making on the one hand, and the simultaneous lack of understanding of how and why specific design elements may exert such an effect on the other, the aim of this chapter is to show how an approach inspired by the embodied cognition framework may provide (part of) an answer to these questions. This framework was originally developed in the field of cognitive linguistics (Lakoff \& Johnson, 1980; 1999), and subsequently fine-tuned and tested in the domains of cognitive and social psychology. We will argue that in order to understand why specific look and feel properties of packaging design call forth specific evaluations and (sensory) experiences, we have to go back to primary, bodily experiences and related body-environment interactions. For instance, the widespread usage of rough-feeling, matt surface finishes in packaging design and its association with toughness or masculinity can be understood when realizing that in our 
everyday interactions with objects, rough surfaces feel 'hard' and 'inflexible' on our skin, whereas smooth surfaces rather feel 'soft' and 'supple'. This very brief introspection reveals why we may be inclined to typify a person we have trouble coming to terms with as rough or rugged. More importantly for the present undertaking, it allows us to understand why we may readily associate a black, matt packaging design with a masculine or rugged brand personality. In other words, the embodied cognition framework postulates that bodily states or experiences (e.g., a sharp or intense sensation on our skin) occurring in our daily interactions with the environment (e.g., when interacting with objects) are at the basis of symbolic or abstract meaning attributions to objects (e.g. perceiving an object as masculine or rugged; Barsalou, 2008; Van Rompay \& Ludden, 2015). Although there are different views on embodied cognition (Wilson, 2002), they all share the notion that cognitive representations are fundamentally grounded in their physical context (cf. Niedenthal et al., 2005).

Another central tenet in our line of reasoning revolves around how these 'embodied' expectations (triggered by multisensory aspects of packaging design) subsequently 'transfer' to sensory experiences issuing forth from the consumption of the contents. Such transfer effects from packaging to taste have been repeatedly demonstrated for different types of products and design factors. For instance, Piquereas-Fiszman and Spence (2012) demonstrated a relationship between packaging texture and taste perception by showing that biscuits in a rough package were rated as being crisper than identical biscuits sampled from a smooth package instead. Likewise, Van Rompay et al. (2017) recently demonstrated that a bitter coffee was perceived as more bitter in a sample cup with an angular, rather than a rounded, tactile pattern on the outer surface. Thus, interaction with the container (i.e., cup or package) can generate expectations and these expectations then modulate subsequent consumption experiences. 
As illustrated by these examples, this sequence usually involves an automatic process in which consumers draw on initial impressions (derived from packaging design) which then generate expectations that colour their subsequent evaluations (e.g., product feel or taste; Huber \& McCann, 1982; Pinson, 1986). However, sometimes we may discount a first impression and its source (i.e., the package), and more deliberately evaluate a product and its contents. For instance, the 'green' image suggested by the package of an (unhealthy) snack encountered in a supermarket may instil doubt or scepticism, leading to a more thorough evaluation of the snack's taste in which we try to 'discount' the package as a reliable source of information. Hence, we will also discuss those studies suggesting that, depending on design of packaging and environment, different types of information processing may be activated. On a more general level, the workings of packaging design may also vary as a function of personality, values, or concerns (e.g., think here only of organic shoppers and their concerns for eco-friendly food consumption).

In the remainder of this chapter, we will discuss these notions and questions in relation to three different dimensions of packaging design: overall packaging shape, graphic layout and composition, and tactile packaging properties. Although packaging experience may also comprise smell and sound, vision and touch may well be most amenable to the embodied account discussed here (as also suggested by the relatively large number of studies addressing these sense modalities in particular). In each case, we will discuss the embodied basis of the findings and notions discussed, followed by evidence from experimental research from the food and beverage context, or from research in related disciplines (e.g., design research or social psychology). We close the review with, as of yet, unexplored directions for future research and product development in the context of healthy lifestyle management. Before zooming-in on packaging design, we will first situate the embodied cognition perspective within the broader context of consumer decision making and automatic processes. 


\section{A situated, embodied perspective on consumer judgment and decision making}

Most of the studies discussed in this chapter share at least two key features: a) seemingly trivial or subtle packaging cues can have a strong impact on (sensory) product evaluation, and b) consumers are generally unware of such effects. When asked, in fact, they often deny (or are surprised) that subtle packaging cues influenced their evaluations. These overall findings fully align with the emerging picture of human judgment and decisionmaking which radically contrasts with the classical economic notion of consumers optimizing utility functions and thus forming stable and well-defined preferences (Persky, 1995). Instead, this picture emphasizes the seemingly irrational, haphazard, and volatile nature of much of consumer behaviour.

Stretching out way beyond the confines of multisensory packaging design, consumer psychology is replete with such 'surprising' findings. For instance, consumers have been shown to prefer brand names starting with their own name letter (Brendl, Chattopadhyay, Pelham, \& Carvallo, 2005), buy more French wine when French, instead of German music is played in the supermarket (North, Hargreaves, \& McKendrick, 1999), become more creative after being exposed to the Apple, rather than the IBM logo (Fitzsimons, Chartrand, \& Fitzsimons, 2008), and drink more Liptonice after having been exposed subliminally to the Liptonice brand (Karremans, Stroebe, \& Claus, 2006). These examples are at odds with the notion of consumers as rational, thoughtful decision makers, and instead stress the overwhelming influence of incidental contextual factors on consumer behaviour. Moreover, they point to involuntary, automatic processes that account for this influence and that unfold outside consumer awareness.

This emerging picture is sometimes portrayed as so unstable, haphazard, and idiosyncratic that some scholars have been tempted to label these unconscious effects as "noise” that merely distracts from the value of conscious decision making in understanding 
consumer behaviour (e.g., Simonson, 2005). We disagree with this qualification. Instead, we view such effects as music (rather than noise), although understanding its orchestration and arrangements sometimes requires venturing in some previously unexplored places. One of these (relatively) unexplored places, we will argue in this chapter, is the domain of the human body and its interrelatedness with the environment.

\section{Grounded cognition in consumer behaviour}

An emerging and promising perspective from which to try and understand the impact of design features on consumer perception, judgment, and choice (which also takes centre stage in the present contribution) is that of socially situated, or grounded cognition, of which the embodied perspective is part and parcel (Smith \& Semin, 2004). In short, this perspective holds that the consumer cognition that drives such judgment and choice is malleable, distributed, embodied, and highly sensitive to the demands of the situation. Hence, all cognition is situated or grounded in reality, encompassing both the physical and social environment, as well as the bodily states in which it emerges. The embodied perspective is but one (albeit fascinating) possibility via which consumer cognition is shaped "on the fly" by its integration with environmental stimuli.

Note that this perspective assumes that such grounded cognition is highly adaptive as it enables the consumer to quickly and efficiently cope with sometimes rapidly changing social situations (Smith \& Semin, 2004). Indeed, only when grounded in social reality and the self, can people respond effectively to threats and opportunities as and when they occur, and interrupt ongoing behaviour when needed. In addition, this context-dependency does not mean that consumers are a slave of the situation, but it does mean that consumer goals, preferences and predispositions are not immutably given but may interact with situational demands and features to jointly shape perception, judgment, and behaviour. Many of the 
studies discussed in this chapter illustrate how embodied cognition 'allows' people to anticipate on near-future sensations and experiences (based on design cues comprised by product packaging). It is this adaptability and interdependence between consumer experience and the environment (cf. Smith \& Semin, 2004) that nicely aligns with basic tenets in behavioural biology and evolutionary functionalism, which highlight how humans can flexibly adapt, anticipate, and deal with the challenges of rapidly changing environments. The consumer psychological consequence of adopting his paradigm, though, is that we need to focus on the consumer-environment interface as the object of study in order to further our understanding of consumer judgment and decision-making. In this contribution, we will zoom in on packaging features and how they interact with consumer-specific processes and properties (such as consumer personality and values) in shaping (sensory) product evaluation and experience.

\section{Overall packaging shape and embodied meaning portrayal}

Starting out at the level of the overall product or packaging design, the first (and most direct) type of embodiment reflects consumers' inclination to easily detect human features or traits in products, a tendency generally referred to as personification or anthropomorphism (Aggarwal \& McGill, 2007; Guthrie, 1993). The classic Coca Cola bottle resembling the female body outline is a well-known example from the domain of packaging. Similarly, all of us will be familiar with the anthropomorphic features of automobile design, particularly the front appearance which typically reminds consumers of human face-like features (represented in headlights and grille), either conveying, depending on the brand and its positioning, an impression of affiliation and benevolence, or, conversely, aggression, competition, and dominance (Aggarwal \&McGill, 2007). More recently, Karim, Luetzenkirchen, Khedr, and Khalil (2017) provided empirical evidence for the notion that using watches in 
advertisements with a time setting resembling a smiling face (i.e.,10:10) can positively influence consumer responses.

When turning to the food and beverage context, a brief trip to a supermarket suffices to encounter numerous other examples, ranging from soap and shampoo dispensers to mayonnaise and ketchup bottles resembling human (or animal) bodies or parts thereof. And indeed, Salgado-Montego et al. (20115) showed that participants rate such products (tea, shampoo, and juice in their study) more positively and choose these more frequently when they display a smile-like concave line rather than a frown-like convex line.

Apart from generating a smile on one's face or making a product stand out on the shelf, such endeavours may also appeal to consumer concerns for healthy food consumption and dieting. In particular, Ooijen, Fransen, Verlegh, and Smit (2017) recently showed that packaging shape can serve as a cue that communicates the healthiness of food products. Inspired by embodiment accounts, they demonstrated that slim packaging designs (resembling slim human bodies), as opposed to wide packaging designs, trigger perceptions of product healthiness and are more readily perceived as 'light' or 'low-calorie' variants. Importantly, however, effects of packaging shape on choice likelihood and attitude only transpired for those consumers entertaining health-relevant shopping goals (i.e., a concern for healthy food consumption and/or a fit, slim body); packaging shape did not affect responses for consumers driven by hedonic shopping goals (i.e., consumers looking for a moment of sweet indulgence or delight). In other words, people may be more-or-less attuned to specific design factors depending on the extent to which the meanings they connote match related and, at the time, active concerns or goals.

At a more abstract level (i.e., where there is no explicit resemblance between product and human body), overall product or packaging shape may also trigger specific meaning attributions. Most notably in the writings of gestalt psychologist Rudolf Arnheim (1969, 
1974), relationships between overall shape features (such as orientation, balance, and closure) and specific meaning attributions are proposed. For instance, in relation to the perception of works of art, Arnheim (1974) argues that properly balanced compositions are perceived as at rest or still, whereas unbalanced compositions are perceived as restless. Indeed, similar couplings between balance and meanings such as still, stable and trustworthy have been demonstrated in experimental studies with respect to overall product shape (Van Rompay, Hekkert, Saakes, \& Russo, 2005). Such couplings are (at least in part) embodied as they find their origins in our own perceptions of bodily balance and related feelings of stability or the lack thereof.

As another example of how overall packaging shape can generate attributions of meaning, consider product orientation (i.e., horizontal versus vertical orientation) and its relatedness to power-related constructs such as dominance, luxury and exclusivity (e.g., Van Rompay, De Vries, Bontekoe, \& Tanja-Dijkstra, 2012). To understand why this dimension is persuasive in product perception, think only of linguistic phrases such as 'she is looking down on others' (dominance), 'we made it to the top/it's lonely at the top' (success/exclusivity), or a high-end/up-scale fashion store (luxury). Such expressions are rooted in our own physical interactions in and with the environment where we, for instance, experience a higher sense of control or power over others when positioned high above them. At the same time, 'rising' or 'going up' entails overcoming gravitational forces and thus requires strength and perseverance. For that reason, we intuitively understand why it is 'lonely at the top' or why 'reaching the top' (or 'climbing the social ladder') equals being successful and perseverant.

Not only is this relationship language-independent (Lakoff \& Johnson, 1999), it has also been shown to apply to product and packaging design (Machiels \& Orth, 2017; Van Rompay et al., 2005; Van Rompay \& Pruyn, 2011). For instance, Van Rompay and Pruyn 
(2011) demonstrated that a fictitious bottled water brand is more readily perceived as luxurious, and elicits higher price expectations, when it comes in a tall, elongated bottle shape rather than in a more compact bottle shape. Machiels and Orth (2017) illustrated how perceptions of verticality may also be induced through the environmental context.

Specifically, their findings show that consumers’ power and quality perceptions are enhanced when a package is placed on a shelf that is vertically rather than horizontally orientated. It would certainly be interesting to study the extent to which such verticality cues also drive taste perceptions. Are consumers, for instance, more inclined to describe the taste of coffee as refined, exclusive or sophisticated when associated with a package portraying verticality cues? Or conversely, do they rate the same coffee as tasting more flat, nondescript, and common, when packaging is more horizontally oriented? As to these possibilities, upscale coffee brand Nespresso appears to allude to the former, rather than the latter option (further strengthened by their 'high design by Nespresso' slogan) as apparent from their verticallyoriented (advertising, packaging, and store) designs.

Finally, consider another (related) structural variable; orthogonal versus oblique orientation. Specifically, Joye, Fennis, Redies, and Kreuer (under review) showed that the relative orthogonal (vs. oblique) compositional orientation of CD album cover art affects the audience's perceptions of the music on those CD’s. This research builds on the established perceptual phenomenon that organisms (ranging from goldfish to humans) show a preference and processing advantage when dealing with orthogonal, as opposed to obliquely-oriented visual stimuli, a phenomenon known as the "oblique effect” (Appelle, 1972). The authors demonstrated that this effect is not tied to perceptual facilitation and increased perceptual performance per se, but spills over to affect cross-modal aesthetic preferences. In a series of experimental and cross-sectional studies using secondary data, the authors showed that consumers listened longer to tracks on a (fictitious) new music CD, and liked these tracks 
more, when exposed to an album cover that was orthogonally, rather than obliquely, oriented. Moreover, systematically comparing more than 350 international music CD’s revealed that albums with more orthogonally oriented CD covers (as identified with a new efficient scanning and assessment tool) ended up higher in the music charts (i.e., those of the US, UK, and Germany, and controlling for a number of evident confounding variables). Furthermore, they were rated higher by musical experts (i.e., those from Rolling Stone magazine) than their more obliquely-oriented counterparts.

Translated to the current context, would an orthogonal orientation also enhance taste liking and quality perceptions?

\section{Packaging shape and taste}

The studies discussed so far did not assess the extent to which (embodied) meanings communicated by design also impact actual sensorial product experiences. Inspired by work on crossmodal correspondence (whereby impressions generated by one sense, such as meanings connoted by a product's visual appearance, transfer to, for instance, the taste of a product; Schifferstein \& Spence, 2008; Spence, 2012), Becker, Van Rompay, Schifferstein, and Galetzka (2011) tested whether meanings connoted by shape angularity transfer to taste intensity evaluations. Specifically, they departed from the notion that angular form features are readily associated with potency-related meanings such as tough, powerful, and intense (Bar \& Neta, 2006; Zhang, Feick, \& Price, 2006). The relationship between angularity and potency is embodied in so far angular (as opposed to rounded) shapes generate a more intense, sharp impression on our skin while interacting with them. Such interactions may vary from handling or holding a stone or small object in our hands, to a child at play smashing her head against a sharp-edged coffee table. On a visual level, angular shapes have been likewise 
associated with power-related constructs such as confrontation and conflict (Zhang et al., 2006).

To test whether meanings connoted by packaging design transfer to taste, Becker et al. (2011) presented an identical yoghurt associated with either a rounded or angular package (displayed on a laptop screen) to shoppers at a supermarket (see Figure 1). The findings revealed that yoghurt associated with the angular package was indeed rated as stronger in taste compared to (the identical) yoghurt associated with the rounded package, although these effects were particularly strong for shoppers with a high sensitivity to design (as reflected in high scores on items such as 'Sometimes the way a product looks seems to reach out and grab me’; Bloch, Brunel, \& Arnold, 2003). Hence, because we experience angular objects in our everyday interactions as more forceful, we also tend to rate food or beverage contents associated with angular packaging designs in line with this construct (see Velasco, Woods, Petit, Cheok, \& Spence, 2016 for a review on the relationship between shape and taste).
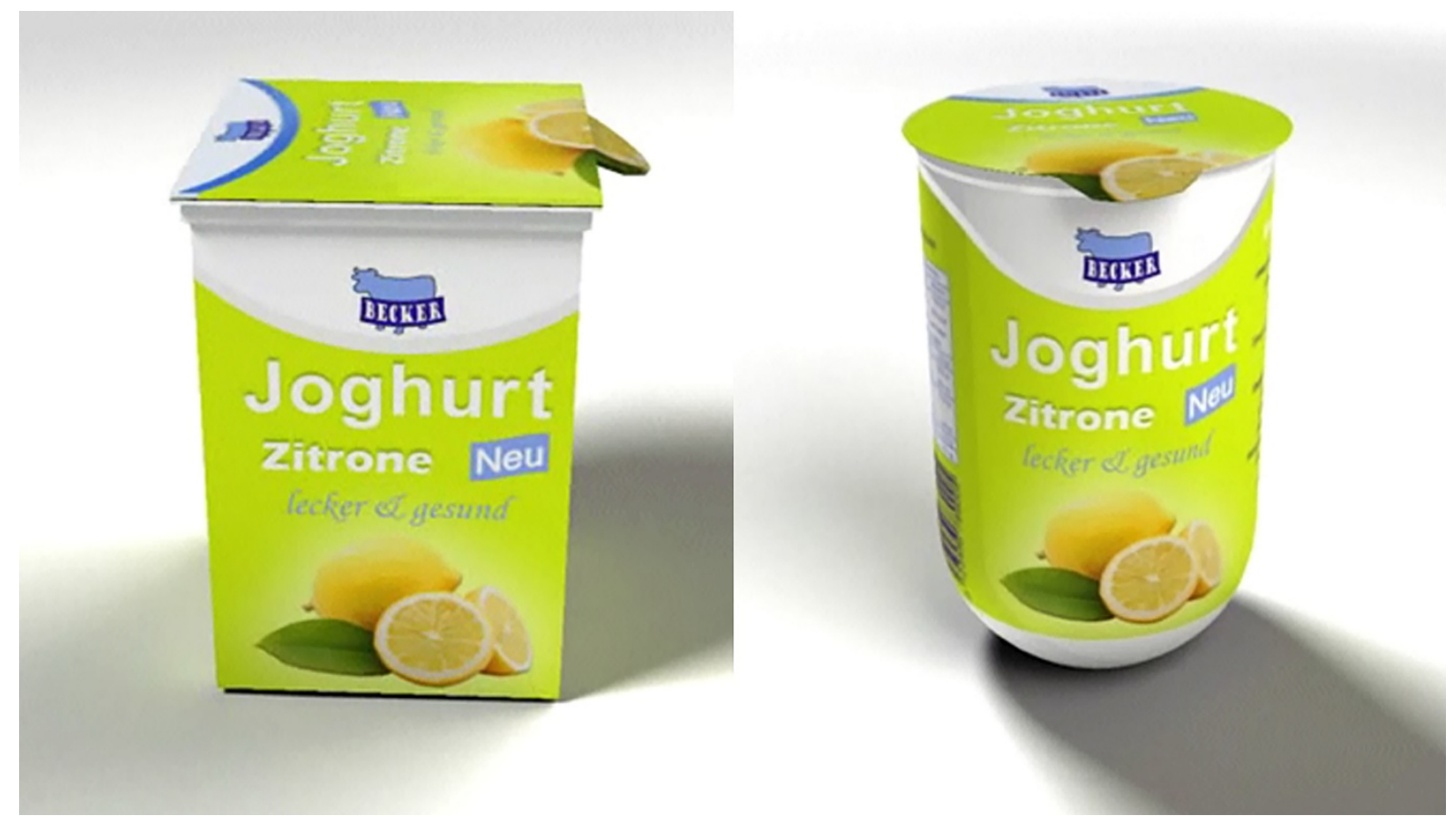

FIGURE 1 
These combined findings testify to the means for embodied meaning portrayal via overall (packaging) design, and for influencing taste and aesthetic evaluations. At the same time, however, consumers may be more or less attuned to such relatively subtle design manipulations either because the values these meanings connect to are more or less salient (Ooijen et al., 2017), or because consumers may be more or less attuned to design manipulations in general (Becker et al., 2011).

\section{Graphic layout and composition}

A package’s physical 3D appearance makes for a close kinship between packaging design and product design. However, when we focus on the visual, graphic part of a package (where brand and product-related visuals and textual elements such as brand and product information meet), packaging design leans heavily towards the visual arts and advertising design. When looking back at the packaging variants presented in Figure 1, it is easy to see that design choices in this context include, amongst others, decisions on placement of visuals, orientation and direction of shapes and lines, colour selection, and decisions on visual complexity.

In recent years, a considerable body of research has shown that such decisions are far from trivial and may in fact have a far-reaching impact on brand and product evaluations. As discussed, the notion that the suggestion of movement (versus stability or balance) is an important predictor of visual experience is widespread among artists and researchers interested in the visual arts (Arnheim, 1969; Kandinsky, 1926). But whereas when applied to overall package shape (as discussed in the previous section), means for exploration are limited due to functional constraints (i.e., a packaging has to take in a stable, solid position during transport, on the shelf, and later on in consumers' homes), when studied in relation to graphic design of packaging labels, such constraints disappear and means for exploration are thus endless. 
For instance, recent studies in consumer psychology have stressed the importance of implied movement by graphic design (e.g., through arrows, lines leading the eye from start to end, or frozen depictions of objects in motion) to branding and advertising practices (Cian, Krishna, \& Elder, 2014; Roggeveen, Grewal, Townsend, \& Krishnan, 2015). Cian et al. demonstrated that such movement-suggesting visuals indeed evoke eye movements which, in turn, enhanced consumer engagement (i.e., involvement) with the brand and inspired positive attitudes. In other words, engaging consumers on a physiological, bodily level may likewise foster engagement on the product and brand level. Furthermore, these findings (i.e., eye movements recorded via eye-tracking technology) correspond with the notion that observers (i.e., the visual system) ‘fill in’ or 'simulate’ the trajectory suggested by visual stimuli (Barsalou, 1999; Downing \& Treisman, 1997).

Importantly, however, this engagement-attitude effect varied in strength depending on the extent to which movement was considered brand appropriate. Thus, such movement effects may only work for those brands that are associated with dynamism and activity (a pillar of brand personality; Aaker, 1997; Geuens, Weijters, \& De Wulf, 2009), such as sports brands or brands associated with ongoing innovation and development. Translated to packaging design, these findings suggest that brands highlighting tradition and ancestry may rather benefit from visuals suggesting stillness and stability rather than movement and change.

In elaborating on the embodied basis of such movement effects, consider everyday interactions in which we move from one place to another. In such actions, bodily movement is inherently associated with change of location, and hence with new sensations, new experiences, and new social and physical environments, whereas stillness and stability of bodily positions entail a lack of the 'new' and a focus on the status quo and the familiar. It would certainly be interesting to study whether manipulations of packaging imagery (in terms 
of movement and stillness) affect taste evaluations in a manner that is consistent with this embodied line of reasoning. Thus, when looking back at the dairy package presented in Figure 1 (presenting a very balanced and static ‘green’ scene); would it more readily trigger perceptions of drink taste as original or innovative when depicting imagery in a dynamic rather than static fashion (e.g., by using depictions of 'cow' and 'juicy lemon parts' in motion rather than in 'still life' style)? And considering the intuitive coupling between health and movement (i.e., physical exercise), would such a redesign for a healthy yoghurt indeed foster engagement with the brand and (thus) inspire healthy food choice?

In addition to the absence or presence of suggested movement, research indicates that the direction of such movement should be considered as well (e.g., Van Rompay, Fransen, \& Borgelink, 2013). Reasoning that in our everyday interactions, the upper realm is readily associated with lightness and lightweight objects (such as leaves gently coming down), Van Rompay et al. (2013) demonstrated that movement visuals presenting upward, rather than downward, movement (embedded on a packaging for washing detergents) triggered perceptions of a less concentrated, fresher smell in a product sample test where shoppers were instructed to open the package and smell its contents (in all cases, an identical neutrallyscented washing powder). Downward movement was associated with a more concentrated 'heavy' smell. These findings are in line with previous research demonstrating a relationship between perceived moment and food freshness (Gvili, Tal, Amar, \& Wansink, 2014), and highlight the importance of movement direction. However, the positive effect of upward movement on smell only surfaced when movement visuals were placed in a corresponding 'light' location on the package: the top-left (as opposed to the bottom-right) region.

The relevance of this latter finding aligns with research assessing location of imagery in consumer packaging (Deng \& Kahn, 2009). To understand the relevance and embodied grounding of this dimension, consider only that people across cultures and regions associate 
similar meanings with basic spatial orientations such as the 'above' and 'below' (Osgood, 1960). The general line of reasoning accounting for this relationship holds that people associate the ground plane (or the lower region in a graphic design) with heaviness and constraint because we ‘learn’ from our bodily experiences that going up takes effort, and all the more so with increasing (bodily) weight or accompanying load (e.g., cycling uphill with a full shopping bag). Hence, we tend to associate heights with lightness or objects free from the forces of gravity, whereas the ground plane is readily associated with heaviness and people or objects that due to their weight are restricted to the ground plane.

Deng and Kahn (2009) illustrated that these principles also apply to the perception of product packaging. Specifically, they showed that product packaging appears more or less weighty dependent on whether imagery is presented in 'light' (top, top-left) or 'heavy' (bottom, bottom-right) locations. Building forth on these findings, Van Rompay et al. (2013) demonstrated (in addition to the 'movement-smell' effect discussed earlier) that shoppers actually experienced a packaging as heavier (i.e., as containing more washing powder) when the imagery was placed on the bottom part of the package rather than at the top. Specifically, participants were instructed to pick up the package and provide an estimation of packaging weight.

Fenko, De Vries, and Van Rompay (2018) showed that such perceptions may also translate to taste experience. Specifically, coffee taste was evaluated as stronger in a taste test when associated with a visually heavy package (with imagery presented at the bottom rather than at the top; see Figure 2). 


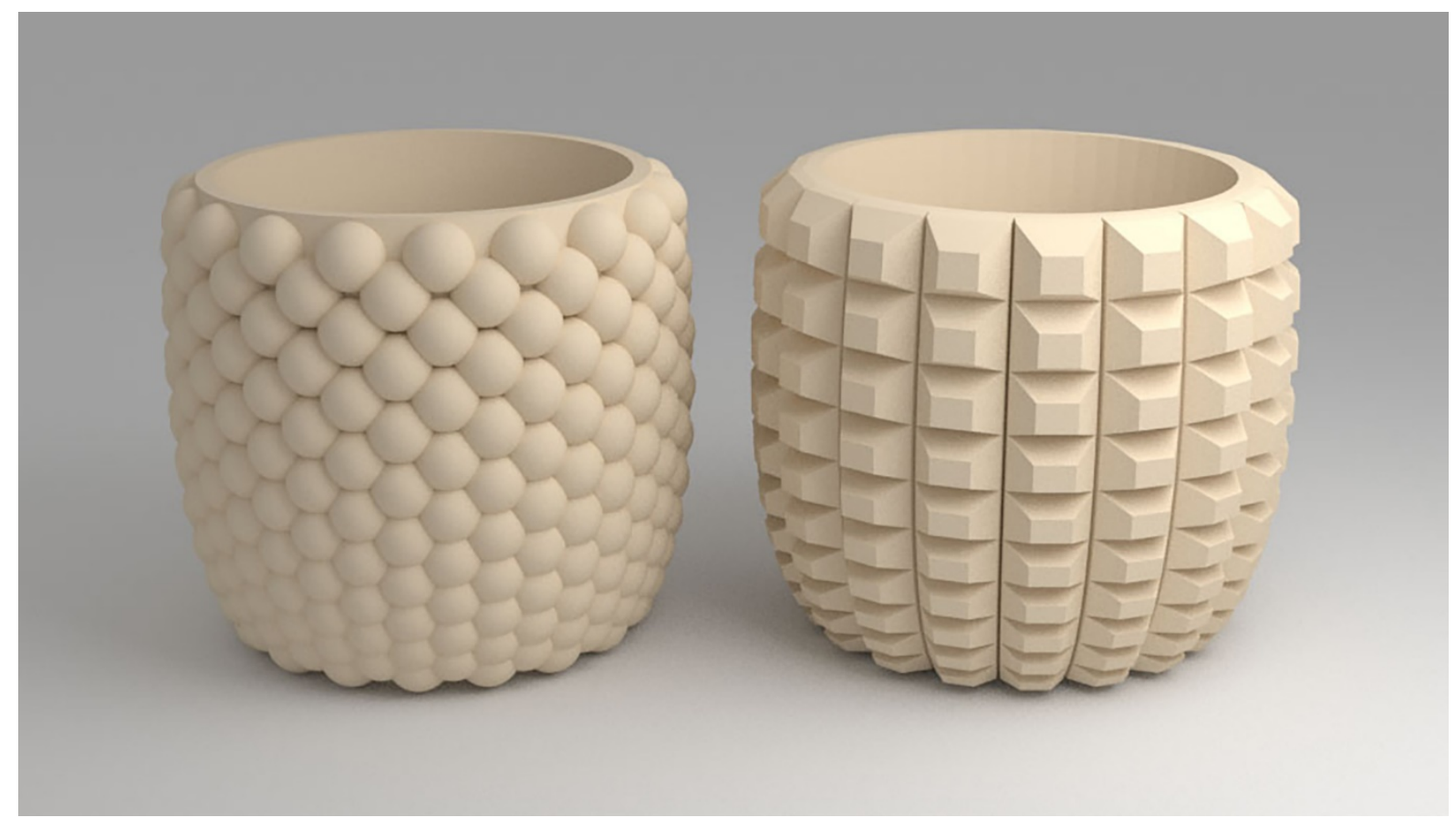

FIGURE 2

Finally, and of particular interest to initiatives centred on healthy food consumption, Karnal, Machiels, Orth, and Mai (2016) illustrated that heaviness perceptions may also follow from colour selection and typeface usage. In line with van Ooijen et al. (2017), Karnal et al. (2016) demonstrated, amongst others, that heavy (bold) typefaces are readily associated with nonhealthy (sugary) product variants, but only so for consumers aiming at good health (i.e., consumers with a health promotion focus). These findings once again demonstrate that different design cues can activate health perceptions, but that a corresponding consumer focus on health might be required.

\section{Tactile design and surface textures}

In the previous sections, the emphasis was on how visual appearances may affect product and brand perception, and sensorial evaluations comprising taste, smell, and haptic sensations (i.e., the perception of volume). However, recent developments in 3D printing and coating technologies increasingly enable tactile manipulations in packaging design as well. In line with such developments, a variety of studies have demonstrated that different materials 
make for qualitatively different taste experiences (Biggs, Juravle, \& Spence, 2016; PiquerasFiszman \& Spence, 2012; Schifferstein, 2009; Spence \& Wan, 2015; Tu, Yang, \& Ma). For instance, in studies by Schifferstein (2009) and Tu et al. (2015), participants tasted drinks from cups made of different materials. Whereas Schifferstein (2009) showed that participants enjoyed their soda better when drunk from a plastic (rather than ceramic) cup, Tu et al. (2015) demonstrated that participants evaluated ice tea contained in glass cups as tasting sweeter compared to cold tea contained in plastic cups (while controlling for weight). These findings testify to the importance of material selection. However, when it comes to tactile sensations originating from surface textures or patterns (which can be applied on the same type of material, see Figure 3), experimental research is limited (cf. Spence \& Wan, 2015; Spence, 2016).

For that reason, Van Rompay et al. (2017) recently applied 3D printing technology to generate systematic variations in surface textures embedded in sample cups, and subsequently used these containers during a taste test for fictitious coffee and hot chocolate brands. The findings revealed, amongst others, that a bitter coffee was perceived as more bitter (and more intense) in a sample cup with an angular surface texture (Figure 3, left panel), whereas a sweet chocolate became even sweeter when tasted from a sample cup with rounded tactile elements (Figure 3, right panel). 


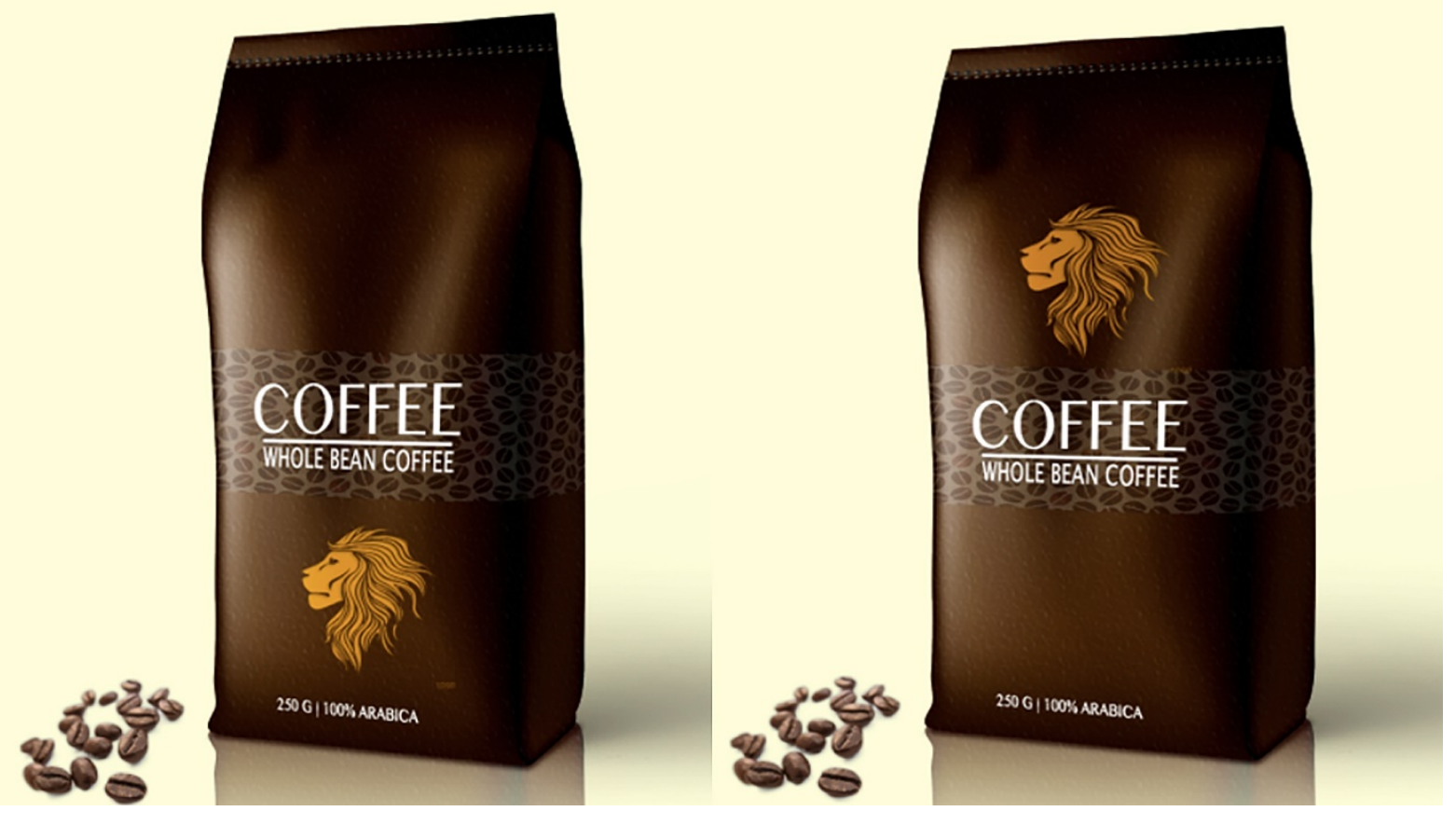

FIGURE 3

These findings illustrate that tactile elements may accentuate the perception of basic taste. Specifically, the finding that an angular (as opposed to a rounded) 3D-printed pattern resulted in a more bitter taste experience was explained by arguing that an angular texture creates a sharper, more intense experience on the skin, and that therefore consumers evaluate the taste as more bitter (a taste dimension high on intensity; cf. Ngo, Misra, \& Spence, 2011). Sweetness, on the other hand, is generally experienced as more harmonious, soft, and round, and for that reason, sweetness ratings were arguably accentuated by the rounded surface pattern (however, see Machiels (2018) for research where round cups failed to induce a sweeter taste). Note that these findings on angularity (of tactile micro elements) are fully in line with Becker et al. (2011) in which the same line of (embodied) reasoning was used to account for effects of an overall angular packaging shape on taste intensity (see Figure 1).

Furthermore, findings from this study (again) confirmed the importance of congruence or fit between (tactile) design and product type (cf. Cian et al. 2014).

Specifically, an angular surface texture better matched the overall bitterness of a coffee drink, 
whereas a rounded surface texture better matched the overall sweetness of a chocolate drink. Importantly, these matching combinations (e.g., a sweet chocolate drink tasted from a cup with rounded tactile elements) elicited more favourable taste and product evaluations compared to non-matching combinations (e.g., bitter coffee tasted from a cup with rounded tactile elements).

In addition to such 'design-product type’ matches, the importance of coherence or congruence among different design elements making up a product or package (e.g., fit between shape and typeface design; Van Rompay \& Pruyn, 2011) has been well established (e.g., Hekkert, 2006). To better understand (both types of) congruence effects, the processing fluency framework is of particular interest (Reber, Schwarz, \& Winkielman, 2004). According to this account, those stimuli that can be easily processed elicit positive affect (because fluent processing indicates that things in the environment pose no danger or cognitive challenges), which is subsequently attributed to the stimulus at hand, resulting in favourable product evaluations (e.g., Lee \& Labroo, 2004; Reber et al., 2004). When consumers face the task of integrating meanings connoted across, for instance, package materials, visuals, and product type into an overall impression, congruence facilitates impression formation (and this enhances product appeal), whereas mixed signals (i.e., incongruences) in terms of meaning portrayals elicit ambiguity with respect to product identity, prompting deliberative and effortful inference making (cf. Vallacher \& Wegner, 1985), and thus thwarting automatic impression formation.

Now that we have come to the end of this chapter, it should be noted that we have presented a relatively straightforward story in which sensory impressions and meanings are relatively easily traced to their embodied underpinnings. Furthermore, the findings presented suggest that a fit between different (design) elements is key to product success. In the final section, however, we will further elaborate on types of information processing instigated by 
design and discuss research warning against an oversimplified version of the role of design in food and beverage evaluation.

\section{Discussion}

Throughout this chapter, we showed how the embodied cognition framework may help us to account for (and thus also to anticipate) effects of design variables on product evaluation and sensory impressions in particular. To this end, a series of studies was discussed in which design variables, meaning portrayals, and sensory impressions were traced to their embodied underpinnings. Along the way, implications for research on healthy food consumption were hinted at. For instance, findings on tactile design and sweetness impressions may be relevant as far as they suggest that negative effects of reduced (artificial) sugar levels on taste may (at least to some extent) be remedied through packaging design. Likewise, effects of shape angularity (intensifying taste intensity) may perhaps counteract impressions of taste 'blandness' which consumers often report when tasting organic or healthy foods.

At the same time, however, it is also true that for other outcome measures important to health initiatives in the food context, the relevance of these findings is less straightforward. For instance, what about initiatives to reduce the salt content of foods (which are particularly high in processed foods)? How do impressions of saltiness relate to design factors, if at all? And even where relationships between health-relevant taste sensations and design are more straightforward, it should be acknowledged that so far, experimental, controlled studies in this specific context (involving effects of implicit design cues on healthy food consumption) are non-existent as far as we know.

Furthermore, the relationship between design and taste is in all likelihood more complex than perhaps suggested in this chapter. That is, in all studies discussed, transfer effects from impressions generated by exposure to packaging appearance to sensory 
evaluations were apparent. Thus, for instance, potency-related meanings triggered upon perception of an angular packaging shape, 'transferred' to the evaluation of product taste (and hence triggered a stronger taste experience). But although such cross-modal correspondences (in which evaluations in one sense modality 'follow' those in another) have been demonstrated frequently, this is not to say that this is always the case. Particularly noteworthy are those findings from studies (e.g., Cardello \& Sawyer, 1992; Davidenko et al., 2015; Yeomans, Chambers, Blumenthal, \& Blake, 2008) showing that when the discrepancy between expectations (formed prior to tasting) and subsequent sensorial impressions becomes too large, a contrast (rather than assimilation) effect occurs (see Piqueras-Fiszman and Spence (2015) for a review on sensory expectations based on product-extrinsic food cues).

To illustrate, Yeomans et al. (2008) studied the interplay between food labels and taste evaluations and they showed, for instance, that when confronted with a particular icecream label, strong expectations of a sweet, fruity flavour were generated. When participants next tasted a (very unexpected) salty ice cream, saltiness ratings (as opposed to sweetness ratings) were further enhanced, clearly demonstrative of a contrast effect. A way to make sense of such findings is by realizing that in many encounters between shoppers and consumer products, processing occurs foremost in an automatic fashion involving little deliberate decision making.

However, when sensations triggered by food tasting radically diverge from initial expectations, processing can arguably not proceed in a fluent, automatic fashion (Vallacher \& Wegner, 1985), but instead requires deliberate 'intervention’ to make sense of the encountered incongruence. Arguably, it is then that the source of the initial expectation (i.e., the package) is discounted and the taste is more critically evaluated. Under such circumstances, overcompensation may occur (resulting from attempts to factor out the role of the package when evaluating taste). A similar process has been observed in priming studies 
where consumers (once aware of the presence of a priming effect) overcompensate for the influence exerted by the prime (i.e., reverse priming may be observed; Glaser \& Banaji, 1999). In other words, these findings warn against oversimplified conclusions based on findings from studies demonstrating straightforward transfer effects from design to taste evaluation. Instead, they stress the importance of carefully managing and testing effects of design on taste evaluation. Clearly such practices should take into account the gap between taste expectations and 'actual' taste.

Additionally, we have discussed moderators of design effects on product and taste evaluation such as consumer values, personality, and environmental context. This latter factor is relatively neglected in research but may well be of critical importance as packaged products are usually encountered in supermarkets where consumer involvement and time spent on inspection of packaging appearance is generally very limited. Moreover, recent findings suggest that dependent on environmental setting, extent of consumer processing of packaging design may vary. For instance, Van Rompay, Deterink, and Fenko (2016) compared the effects of packaging design at a discount supermarket versus at an organic supermarket. Their findings revealed that effects of packaging design on taste evaluation surfaced at the discount supermarket only, suggesting that at the organic supermarket, the package was discounted as a source of taste evaluation.

To rule out that this effect was fully the resultant of different shopper segments (frequenting the respective supermarkets) with different health concerns (cf. Ooijen et al., 2017), a follow-up lab study involving a homogenous group of participants was conducted. These additional findings confirmed that this effect was at least in part due to the environmental context (and not only due to shopper type), indicating that environmental cues may affect extent of processing, trigger scepticism with respect to packaging, or raise health awareness and related concerns. Although shoppers may increasingly shop online for 
groceries, note that also here means for incorporating (health-related) design cues (i.e., web atmospherics comprising color, shape, and product visualizations) are plenty (see Hunter \& Mukerji (2011) for a review). This is not to say, however, that healthy food choices should always be associated with stereotypical colors or visualizations. For instance, Tijssen, Zandstra, de Graaf, and Jager (2017) demonstrated that sugar-and-fat reduced products were considered less attractive when presented in a light-blue package, perhaps indicating that some design cues may activate the 'healthy is not tasty' heuristic (Raghunathan, Naylor, \& Hoyer, 2006).

Across several studies (e.g., Karnal et al., 2016; Ooijen et al., 2017), the importance of a focus on health was attested to, indicating that packaging design may foremost act as a diagnostic cue for making healthy food choices when shoppers are aware of the impact of food intake on health and wellbeing while shopping. In line with such findings, in a previous study (Papies \& Hamstra, 2010), exposure to a poster including words like “slim figure”, “extra slim”, and “weight” in a butcher's shop reduced consumption of free meat snacks for chronic dieters, whereas non-dieters were not affected by the prime. Taking note of the supermarket as the environment where most food choices are made, it would be very interesting to study if and how more implicit design elements such as natural color and lighting schemes might also activate a focus on health (i.e., 'health goal priming'; Papies, 2016). In other words, the environment might set the stage (by inducing a health focus), on which packaging design might subsequently come to the fore and lead shoppers towards healthy food choices. Arguably, when using implicit design cues, this process is largely automatic and effortless ('Type 1’ processing) whereas more explicit (textual) cues would rather involve more deliberate decision making ('Type 2’ processing; see Petit et al. [2016]).

In closing this chapter, it is worth noting that recent developments in packaging technology (ranging from the usage of advanced materials to ever more sophisticated 3D 
printing and coating technologies), as well as virtual reality (VR) technology, will increasingly allow for realistic and ecologically-valid fabrications and simulations of a wide range of packaging designs, environmental settings (e.g., supermarkets), and corresponding observations of consumer behaviours and decision making (see Petit et al., this volume, for a review). However, this unprecedented and unlimited range of stimuli and research opportunities all the more calls for insights and frameworks allowing for evidence-based identification of relevant design factors and consumer behaviours. In our opinion, the embodied cognition framework as discussed in this chapter offers great promise in doing so. 


\section{References}

Aaker, J. L. (1997). Dimensions of brand personality. Journal of Marketing Research, 34(3), 347-356.

Appelle, S. (1972). Perception and discrimination as a function of stimulus orientation: The "oblique effect" in man and animals. Psychological Bulletin, 78(4), 266-278. Arnheim, R. (1969). Visual thinking. Berkeley, CA: University of California Press.

Arnheim, R. (1974). Art and visual perception: A psychology of the creative eye. Berkeley, CA: University of California Press.

Bar, M., \& Neta, M. (2006). Humans prefer curved visual objects. Psychological Science, 17(8), 645-648.

Barsalou, L. W. (1999). Perceptual symbol systems. Behavioral and Brain Sciences, 22(4), 577-609.

Barsalou, L. W. (2008). Grounded cognition. Annual Review of Psychology, 59, 617645.

Becker, L., van Rompay, T. J., Schifferstein, H. N., \& Galetzka, M. (2011). Tough package, strong taste: The influence of packaging design on taste impressions and product evaluations. Food Quality and Preference, 22(1), 17-23.

Biggs, L., Juravle, G., \& Spence, C. (2016). Haptic exploration of plateware alters the perceived pattern and taste of food. Food Quality and Preference, 50, 129-134.

Bloch, P. H., Brunel, F. H., \& Arnold, T. J. (2003). Individual differences in the centrality of visual product aesthetics: Concept and measurement. Journal of Consumer Research, 29, 551-565.

Brendl, C. M., Chattopadhyay, A., Pelham, B. W., \& Carvallo, M. (2005). Name letter branding: Valence transfers when product specific needs are active. Journal of Consumer Research, 32(3), 405-415. 
Cardello, A. V., \& Sawyer, F. M. (1992). Effects of disconfirmed consumer expectations on food acceptability. Journal of Sensory Studies, 7(4), 253-277.

Cian, L., Krishna, A., \& Elder, R. S. (2014). This logo moves me: Dynamic imagery from static images. Journal of Marketing Research, 51(2), 184-197.

Davidenko, O., Delarue, J., Marsset-Baglieri, A., Fromentin, G., Tomé, D., Nadkarni, N., \& Darcel, N. (2015). Assimilation and contrast are on the same scale of food anticipatedexperienced pleasure divergence. Appetite, 90, 160-167.

Deng, X., \& Kahn, B. E. (2009). Is your product on the right side? The "location effect” on perceived product heaviness and package evaluation. Journal of Marketing Research, 46(6), 725-738.

Downing, P., \& Treisman, A. (1997). The line-motion illusion: Attention or impletion? Journal of Experimental Psychology: Human Perception and Performance, 23(3), 768-779.

Fenko, A., De Vries, R., \& Van Rompay, T. (2018). How strong is your coffee? The influence of visual metaphors and textual claims on consumers' flavor perception and product evaluation. Frontiers in Psychology, 9(53); doi:10.3389/fpsyg.2018.00053.

Fitzsimons, G. M., Chartrand T. L., \& Fitzsimons G. J. (2008). Automatic effects of brand exposure on motivated behavior: How Apple makes you think different. Journal of Consumer Research, 35, 21-35.

Glaser, J., \& Banaji, M. R. (1999). When fair is foul and foul is fair: Reverse priming in automatic evaluation. Journal of Personality and Social Psychology, 77, 669-687.

Geuens, M., Weijters, B., \& De Wulf, K. (2009). A new measure of brand personality. International Journal of Research in Marketing, 26(2), 97-107.

Gvili, Y., Tal, A., Amar, M., \& Wansink, B. (2017). Moving up in taste: Enhanced projected taste and freshness of moving food products. Psychology \& Marketing, 34(7), 671683. 
Hekkert, P. (2006). Design aesthetics: Principles of pleasure in product design. Psychology Science, 48, 157-172.

Huber, J., \& McCann, J. (1982). The impact of inferential beliefs on product evaluations. Journal of Marketing Research, 19, 324-333.

Hunter, R., \& Mukerji, B. (2011). The role of atmospherics in influencing consumer behaviour in the online environment. International Journal of Business and Social Science, 2(9), 118-125.

Joye, Y., Fennis, B. M., Kreuer, C., \& Redies, C. (2018). The oblique effect in music album covers as a visual predictor of album peak position and expert ratings. Manuscript under review.

Kandinsky, V. (1926). Point and line to plane. New York, NY: Dover Publications.

Karim, A. A., Luetzenkirchen, B., Khedr, E. M., \& Khalil, R. (2017). Why is 10 past 10 the default setting for clocks and watches in advertisements? A psychological experiment. Frontiers in Psychology, 8:1410. doi: 10.3389/fpsyg.2017.01410.

Karnal, N., Machiels, C. J. A., Orth, U. R., \& Mai, R. (2016). Healthy by design, but only when in focus: Communicating non-verbal health cues through symbolic meaning in packaging. Food Quality and Preference, 52, 106-119.

Karremans, J. C., Stroebe, W., \& Claus, J. (2006). Beyond Vicary’s fantasies: The impact of subliminal priming and brand choice. Journal of Experimental Social Psychology 42, $792-798$.

Krishna, A. (2012). An integrative review of sensory marketing: Engaging the senses to affect perception, judgment and behavior. Journal of Consumer Psychology, 22(3), 332351.

Lakoff, G., \& Johnson, M. (1980). Metaphors we live by. Chicago, IL: The University of Chicago Press. 
Lakoff, G., \& Johnson, M. (1999). Philosophy in the flesh. New York, NY: Basic Books.

Lee, A. Y., \& Labroo, A. A. (2004). The effect of conceptual and perceptual fluency on brand evaluation. Journal of Marketing Research, 41, 151-165.

Ludden, G. D. S., \& Van Rompay, T. J. L. (2015). How does it feel? Exploring touch on different levels of product experience. Journal of Engineering Design, 26(4-6), 1-12.

Machiels, C. J. A. (2018). Bittersweet findings: Round cups fail to induce sweeter taste. Beverages, 4(12); doi:10.3390/beverages4010012.

Machiels, C. J. A., \& Orth, U. R. (2017). Verticality in product labels and shelves as a metaphorical cue to quality. Journal of Retailing and Consumer Services, 37, 195-203.

Ngo, M. K., Misra, R., \& Spence, C. (2011). Assessing the shapes and speech sounds that people associate with chocolate samples varying in cocoa content. Food Quality and Preference, 22(6), 567-572.

Niedenthal, P. M., Barsalou, L. W., Winkielman, P., Krauth-Gruber, S., \& Ric, F. (2005). Embodiment in attitudes, social perception, and emotion. Personality and Social Psychology Review, 9, 184-211.

North, A. C., Hargreaves, D. J., \& McKendrick, J. (1999). The influence of in-store music on wine selections. Journal of Applied Psychology, 84(2), 271-276.

Ooijen, I., Fransen, M. L., Verlegh, P. W. J., \& Smit, E.G. (2017). Signalling product healthiness through symbolic package cues: Effects of package shape and goal congruence on consumer behaviour. Appetite, 109, 73-82.

Osgood, C. E. (1960). The cross-cultural generality of visual-verbal synesthetic tendencies. Behavioral Science, 5, 146-169. 
Papies, E. (2016). Health goal priming as a situated intervention tool: How to benefit from nonconscious motivational routes to health behavior. Health Psychology Review, 10(4), 408-424.

Papies, E. K., \& Hamstra, P. (2010). Goal priming and eating behavior: Enhancing self-regulation by environmental cues. Health Psychology, 29(4), 384-388.

Peracchio, L. A., \& Meyers-Levy, J. (2005). Using stylistic properties of ad pictures to communicate with consumers. Journal of Consumer Research, 32(1), 29-40.

Persky, J. (1995). The ethology of homo economicus. The Journal of Economic Perspectives, 9(2), 221-231.

Petit, O., Basso, F., Merunka, D., Spence, C., Cheok, A. D., \& Oullier, O. (2016). Pleasure and the control of food intake: An embodied cognition approach to consumer selfregulation. Psychology \& Marketing, 33(8), 608-619.

Pinson, C. (1986). An implicit product theory approach to consumers’ inferential judgments about products. International Journal of Research in Marketing, 3, 19-38.

Piqueras-Fiszman, B., \& Spence, C. (2012). The influence of the feel of product packaging on the perception of the oral-somatosensory pattern of food. Food Quality and Preference, 26, 67-73.

Piquireas-Fiszman, B., \& Spence, C. (2015). Sensory expectations based on productextrinsic food cues: An interdisciplinary review of the empirical evidence and theoretical accounts. Food Quality and Preference, 40, 165-179.

Raghunathan, R., Naylor, R. W., \& Hoyer, W. D. (2006). The unhealthy = tasty intuition and its effects on taste inferences, enjoyment, and choice of food products. Journal of Marketing, 70(4), 170-184. 
Reber, R., Schwarz, N., \& Winkielman, P. (2004). Processing fluency and aesthetic pleasure: Is beauty in the perceiver's processing experience? Personality and Social Psychology Review, 8, 364-382.

Roggeveen, A. L., Grewal, D., Townsend, C., \& Krishnan, R. (2015) The impact of dynamic presentation format on consumer preferences for hedonic products and services. Journal of Marketing, 79(6), 34-49.

Salgado-Montejo, A., León, I. T., Elliot, A. J., Salgado, C. J., \& Spence, C. (2015). Smiles over frowns: When curved lines influence product preference. Psychology \& Marketing, 32(7), 771-781.

Schifferstein, H. N. J., \& Spence, C. (2008). Multisensory product experience. In H. N. J. Schifferstein \& P. P. M. Hekkert (Eds.), Product experience (pp. 133-161). Amsterdam, NL: Elsevier.

Schifferstein, H. N. (2009). The drinking experience: Cup or content? Food Quality and Preference, 20(3), 268-276.

Simonson, I. (2005). Determinants of customers’ responses to customized offers: Conceptual framework and research propositions. Journal of Marketing, 69(1), 32-45.

Smith, E. R., \& Semin, G. R. (2004). Socially situated cognition: Cognition in its social context. In M. P. Zanna (Ed.), Advances in experimental social psychology (Vol. 36, pp. 53-117). San Diego, CA: Elsevier Academic Press.

Spence, C. (2012). Managing sensory expectations concerning products and brands: Capitalizing on the potential of sound and shape symbolism. Journal of Consumer Psychology, 22, 37-54.

Spence, C. (2016). Multisensory packaging design: Color, shape, pattern, sound, and smell. In P. Burgess (Ed.), Integrating the packaging and product experience in food and beverages: A road-map to consumer satisfaction (pp. 1-22). USA: Woodhead Publishing. 
Spence, C., \& Gallace, A. (2011a). Multi-sensory design: Reaching out to touch the consumer. Psychology \& Marketing, 28(3), 267-308.

Spence, C., \& Gallace, A. (2011b). Tasting shapes and words. Food Quality and Preference, 22, 290-295.

Spence, C., Ngo, M. K., Percival, B., \& Smith, B. (2013). Crossmodal correspondences: Assessing shape symbolism for cheese. Food Quality and Preference, 28(1), 206-212.

Spence, C., \& Wan, X. (2015). Beverage perception and consumption: The influence of the container on the perception of the contents. Food Quality and Preference, 39, 206-212.

Tijssen, I., Zandstra, E. H., de Graaf, C., \& Jager, G. (2017). Why a 'light’ product package should not be light blue: Effects of package colour on perceived healthiness and attractiveness of sugar-and fat-reduced products. Food Quality and Preference, 59, 46-58.

Vallacher, R. R., \& Wegner, D. M. (1985). A theory of action identification. Hillsdale, NJ: Erlbaum.

Van Rompay T. J. L., De Vries, P. W., Bontekoe, F., \& Tanja-Dijkstra, K. (2012). Embodied product perception: Effects of verticality cues in advertising and packaging design on consumer impressions and price expectations. Psychology \& Marketing, 29, 919-928.

Van Rompay, T. J. L., Finger, F., Saakes, D., \& Fenko, A. (2017). See me, feel me: Effects of 3D printed surface patterns on beverage evaluation. Food Quality and Preference, 62, 332-339.

Van Rompay, T. J. L., Hekkert, P., Saakes, D., \& Russo, B. (2005). Grounding abstract object characteristics in embodied interactions. Acta Psychologica, 119(3), 315-351.

Van Rompay, T. J. L., \& Ludden, G. D. S. (2015). Types of embodiment in design: The embodied foundations of meaning and affect in product design. International Journal of Design, 9(1), 1-11. 
Van Rompay, T. J. L., Pruyn, A. T. H., \& Tieke, P. (2009). Symbolic meaning integration in design and its influence on product and brand evaluation. International Journal of Design, 3(2), 19-26.

Velasco, C., Woods, A. T., Petit, O., Cheok, A. D., \& Spence, C. (2016). Crossmodal correspondences between taste and shape, and their implications for product packaging: A review. Food Quality and Preference, 52, 17-26.

Wilson, M. (2002). Six views of embodied cognition. Psychonomic Bulletin \& Review, 9, 625-636.

Yeomans, M. R., Chambers, L., Blumenthal, H., \& Blake, A. (2008). The role of expectancy in sensory and hedonic evaluation: The case of smoked salmon ice-cream. Food Quality and Preference, 19(6), 565-573.

Zhang, Y., Feick, L., \& Price, L. J. (2006). The impact of self-construal on aesthetic preference for angular versus rounded shapes. Personality and Social Psychology Bulletin, 32(6), 794-805.

\section{Indexible terms:}

consumer cognition, multisensory experience, taste, visual communication, embodied cognition, psychology, design, food, beverages, sensation, metaphor, symbolic meaning, packaging design, marketing, retailing, branding, attitude formation, brand impressions, nudging, priming, environmental psychology, automatic processes. 